\title{
Iatrogenic catheter sheath shearing during radial artery cannulation
}

\author{
Il-Seok Kim, Ho Kyun Shin, and Dae Yu Kim
}

Department of Anesthesiology and Pain Medicine, Kangdong Sacred Heart Hospital, Hallym University College of Medicine, Seoul, Korea

Radial artery cannulation is a relatively safe procedure following for continuous arterial pressure monitoring and repeated arterial blood gas sampling. In rare cases, however, a sheared catheter sheath during cannulation can result in serious complications such as distal ischemic damage. We experienced a case of iatrogenic catheter sheath shearing during radial artery cannulation due to the reinsertion of a stylet needle through the embedded catheter sheath.

A 74-year-old man was scheduled for pleural decortications of right-side empyema and parapneumonic effusion. Anesthesia was induced with an effect-site propofol concentration of 5.0 $\mu \mathrm{g} / \mathrm{ml}$ and remifentanil $4 \mathrm{ng} / \mathrm{ml}$ using a target controlled infusion pump (Orchestra ${ }^{\circledR}$ Base Primea, Fresenius Vial, Brezins, France). Rocuronium $0.9 \mathrm{mg} / \mathrm{kg}$ was administered intravenously to facilitate tracheal intubation with a left-sided Robert-Shaw double lumen bronchial tube for one-lung ventilation. For continuous arterial pressure monitoring and repeated arterial blood gas sampling, left radial artery cannulation was planned. A 20 gauge angiocatheter (BD Angiocath Plus ${ }^{\mathrm{TM}}$, Becton Dickinson Medical [S] Pte Ltd, Tuas, Singapore) penetrated the skin at a $30^{\circ}$ angle directly over the point at which the pulse was palpated and then advanced slowly toward the pulse. When arterial blood appeared in the flashback chamber of the catheter, the catheter was advanced slightly through the artery. Maintaining the catheter angle at $15^{\circ}$ downward, an attempt was made to advance the catheter sheath over the stylet needle into the artery. However, resistance was felt and advancement of the sheath was halted. Assuming that the sheath lumen was obstructed by a bloody clot or had collapsed due to a narrow artery lumen, the anesthesiologist again advanced the stylet needle back into the catheter sheath. When the needle advanced into the sheath, the anesthesiologist felt strong resistance and then a popping sensation. Upon removal of the catheter, it was found that only $24 \mathrm{~mm}$ of the sheath was removed, and a distal remnant of about $6 \mathrm{~mm}$ was missing (Fig. 1A).

Using an ultrasonographic system (Sonosite ${ }^{\circledR}$ MicroMaxx $^{\mathrm{TM}}$, SonoSite Inc., Bothell, WA, USA) with a 13-6 MHz, $38 \mathrm{~mm}$ broadband linear array transducer (HFL38/13-6 MHz, SonoSite Inc., Bothell, WA, USA), ultrasound imaging revealed that the sheath fragment was not located in the radial artery. It was difficult to identify the exact position, however, because of the inappropriate frequency, the small size of the fragment, and the similar echogenicity between the surrounding soft tissue. A portable C-arm of the left wrist was taken, but the sheath remnant was not revealed on imaging. The pulse of the radial artery was palpated well, and the left hand appeared pink and warm with an acceptable pulse oximetry signal at the thumb and index finger. Considering that the sheath was a radiopaque feature and too small for viewing, a portable X-ray was taken to magnify the X-ray imaging. Before performing the X-ray, arterial cannulation was performed at the left radial artery proximal to the primary punctured site without difficulty. X-ray imaging of the wrist revealed a retained fragment located within the subcutaneous tissue adjacent to the radial artery (Fig. 1B). Judging that the sheath fragment posed an unacceptable risk of distal ischemia, we decided first to proceed with the scheduled operation, and

Corresponding author: Il-Seok Kim, M.D., Department of Anesthesiology and Pain Medicine, Kangdong Sacred Heart Hospital, Hallym University College of Medicine, 445, Gil-dong, Gangdong-gu, Seoul 134-010, Korea. Tel: 82-2-2224-2659, Fax: 82-2-474-0956, E-mail: gns70@hallym.or.kr (c) This is an open-access article distributed under the terms of the Creative Commons Attribution Non-Commercial License (http:// creativecommons.org/licenses/by-nc/3.0/), which permits unrestricted non-commercial use, distribution, and reproduction in any medium, provided the original work is properly cited. 

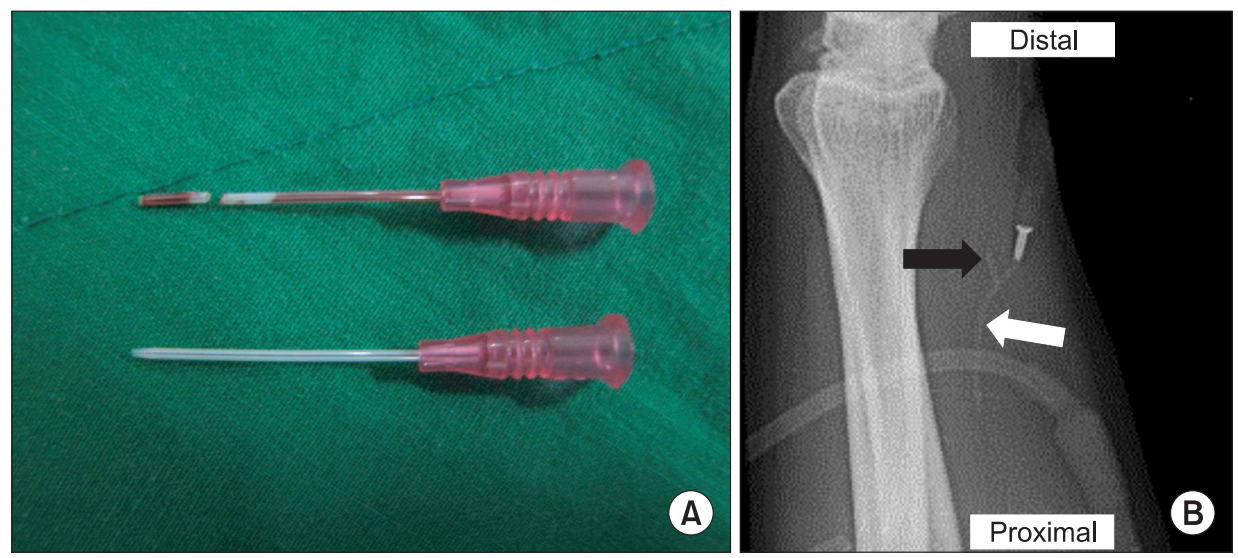

Fig. 1. (A) A sheared catheter sheath and its remnant. A fragmented sheath's lumen is filled with a bloody clot, and its cutting margin has a sharp angle. Upper, the sheared catheter sheath occurring in this case; lower, original 20-gauge angiocatheter sheath. (B) Magnified lateral radiographic images of the wrist. A catheter sheath (white arrow) within the radial artery reinserted proximally to the primary punctured site is seen with a hub. A fragmented sheath (black arrow) is located outside the course of the radial artery.

then perform surgical exploration for the sheath fragment. During the intraoperative period, the hand color did not change, the pulse oximetry signal from the left index finger was normal and oxygen saturation was maintained at $98 \%$ with a $50 \%$ inspired oxygen fraction supplement. The $6 \mathrm{~mm}$ sheath remnant located parallel to the radial artery at the point of insertion, was removed without any complications. The patient recovered uneventfully from both operations and was discharged 2 weeks after the operation.

Several causes for catheter sheath shearing have been reported. Such causes include repeated cannulation attempts and reinsertion of the stylet needle into the damaged catheter sheath, accidentally cutting the catheter sheath with scissors or a stitch cutter during arterial catheter removal, and repeated movement of the wrist $[1,2]$. To prevent ischemic damage to distal circulation, immediate localization of the sheath remnant by radiologic or ultrasonographic evaluation and surgical exploration should be attempted $[3,4]$. In our case, a sheath fragment compacted with a blood clot was embedded in soft tissue beyond the radial artery. Because of the similar echogenicity, it was not possible to identify the exact locations using ultrasound. The small size of the fragment was an additional reason of difficulty for searching fragment. Recently manufactured angiocatheters have a radiopaque feature, enabling discrimination from soft tissue through $\mathrm{X}$-ray film magnification.
In general, there are two accepted techniques for inserting an indwelling catheter into the arterial lumen: an over-the-wire technique and an over-the-needle technique. Both techniques involve puncturing the anterior wall of the artery. With the overthe-needle technique, the artery is punctured through the skin, with the needle inclined at a $30^{\circ}$ to $45^{\circ}$ angle to the skin. Once a flash of blood is seen in the hub of the catheter, the needle should be advanced a few millimeters farther through the artery to ensure that the catheter itself is within the artery. The catheter angle should then be lowered to $10^{\circ}$ to $15^{\circ}$, and the catheter should be advanced over the needle into the artery while holding the needle perfectly still [5]. In our case, we suspect the shearing may have resulted from the reinserted stylet needle cutting off the catheter sheath, which was not straightened in the course of cannulation because the needle was not held perfectly still and the sheath was advanced inappropriately. The removed needle should not be advanced again without blood regurgitation through the catheter. The reinsertion of the stylet needle through the embedded catheter can cause shearing of the catheter sheath. If a sheath fragment is located within the vessel lumen, it can cause embolism and ischemic damage. Considering these facts, anesthesiologist should perform arterial cannulation with an understanding of the relevant anatomy and access procedures. Attention to detail during cannulation and awareness of potential complications can enhance patient safety.

\section{References}

1. Lee SY, Na HS, Kim MH, Kim CS, Jeon TY, Hwang JW, et al. A sheared catheter fragment in the wrist after arterial cannulation attempt -a case report. Korean J Crit Care Med 2010; 25: 118-21.

2. Moon SK, Gong JC, Kim JH, Lee KC, Kim HY, Choi EK, et al. A retained catheter fragment in radial artery caused by accidental catheter transection during arterial catheter removal. J Anesth 2012; 26: 625-6.

3. Moody C, Bhimarasetty C, Deshmukh S. Ultrasound guided location and removal of retained arterial cannula fragment. Anaesthesia 2009; 64: 338-9.

4. Mayne D, Kharwar F. Another complication of radial artery cannulation. Anaesthesia 1997; 52: 89-90.

5. Tegtmeyer K, Brady G, Lai S, Hodo R, Braner D. Videos in Clinical Medicine. Placement of an arterial line. N Engl J Med 2006; 354 : e13. 